\title{
Diffusive isotope fractionation of potassium in molten basalts
}

\author{
YOUXUE ZHANG \\ University of Michigan \\ Presenting Author: youxue@umich.edu
}

Isotope fractionation during diffusion is a fundamental process with numerous applications, including the separation of isotopes, correcting for isotope fractionation in geochronology, understanding isotope fractionation during crystal growth or dissolution, magma interaction and crystal fractionation. In the last two decades, diffusive isotope fractionation has been discovered to be measurable for $\mathrm{Li}, \mathrm{Mg}, \mathrm{Ca}$, and $\mathrm{Fe}$ [1-3], and found to be rather large compared to equilibrium isotope fractionation at high temperature. Still diffusive isotope fractionation is found to be smaller than the Graham's law limit $(b=0.5)$ for isotopes diffusing as atomic species. The measured $\mathrm{b}$ factor [1] in melts is $\leq 0.23$ [3], suggesting diffusion as clusters or exchange. In previous studies, except for $\mathrm{Li}$, isotope ratio measurements in melts were by time-consuming conventional (non-microbeam) methods with low spatial resolution.

We carried out SIMS analyses of ${ }^{41} \mathrm{~K} /{ }^{39} \mathrm{~K}$ isotope ratio profiles in $\mathrm{SiO}_{2}-\mathrm{K}_{2} \mathrm{O}$ and $\mathrm{MgO}-\mathrm{K}_{2} \mathrm{O}$ interdiffusion couple experiments [4,5], with best precision approaching $0.2 \%$ in isotope ratios. Preliminary data show that diffusive ${ }^{41} \mathrm{~K} /{ }^{39} \mathrm{~K}$ fractionation can be as large as $9 \%$ when $\mathrm{K}$ concentration contrast in a diffusion couple is about 70 at a temperature of 1260 to $1500^{\circ} \mathrm{C}$. The data were fit reasonably well using an effective binary diffusion model for each of ${ }^{39} \mathrm{~K}$ and ${ }^{41} \mathrm{~K}$, resulting in a b factor of 0.11 to 0.13 for $\mathrm{SiO}_{2}-\mathrm{K}_{2} \mathrm{O}$ couples with no obvious temperature dependence, and 0.10 to 0.13 for $\mathrm{MgO}-\mathrm{K}_{2} \mathrm{O}$ couples with indication of temperature dependence. These $\mathrm{b}$ factors are consistent with $\mathrm{K}$ diffusing in the melt network as large clusters such as $\mathrm{KAlSiO}_{4}$, or through exchange such as $(1 / 2) \mathrm{Mg}^{2+}$ with $\mathrm{K}^{+}$. The significant fractionation suggests that diffusive $\mathrm{K}$ isotope fractionation during melt mixing is measurable under favorable natural conditions, and such fractionation may impact on $\mathrm{K}$-Ar dating, and may also be used to infer the mixing time scale and cooling history.

\section{References}

1. Richter et al., 1999, GCA, 63, 2853. 2. Watkins et al., 2011, GCA, 75, 3103. 3. Holycross et al., 2018, Geochem. Persp. Lett., 6, 39. 4. Guo and Zhang, GCA, 228, 190. 5. Guo and Zhang, Chem. Geol., 549, 119700. 